\title{
Obstetric anaesthesia claims in French hospitals: a study based on French insurance (SHAM) data
}

Tran L. ${ }^{1}$, Carles M. ${ }^{1}$, Fuz F. ${ }^{2}$, Raucoules M. ${ }^{1}$, Rouquette-Vincenti ${ }^{3}{ }^{3}$, Theissen A. ${ }^{3}$ University Hospital, Dept of Anaesthesiology \& Intensive Care, Nice, France ${ }^{2}$ SHAM Insurance, International Risk Management, Lyon, France, ${ }^{3}$ Princess Grace Hospital, Dept of Anaesthesiology \& Intensive Care, Monaco, Monaco.

\section{Introduction:}

The aim of the study was to analyse closed claims in obstetric anaesthesia provided by SHAM insurance between 2007 and 2014. SHAM insurance is the leading provider of medical liability insurance in France.

\section{Material and methods:}

Retrospective study of SHAM insurance closed claims settled amicably or by a court.

\section{Results:}

Obstetric anaesthesia was involved in 99 cases (Fig 1) among 3,083 obstetric claims over the period (3.2\%). The damage occurred in public hospitals $(54 \%$ in general and $28 \%$ in university hospitals), private hospitals (14\%) or among health professionals (4\%).

The damage occurred during natural childbirth $(60 \%)$, caesarean delivery $(38 \%)$ or an abortion $(2 \%)$. The main type of anaesthesia was epidural $(75 \%)$, spinal anaesthesia $(20 \%)$, general anaesthesia $(3 \%)$ or none $(1 \%)$. The type of anaesthesia involved was regional (93\%) or general $(7 \%)$.

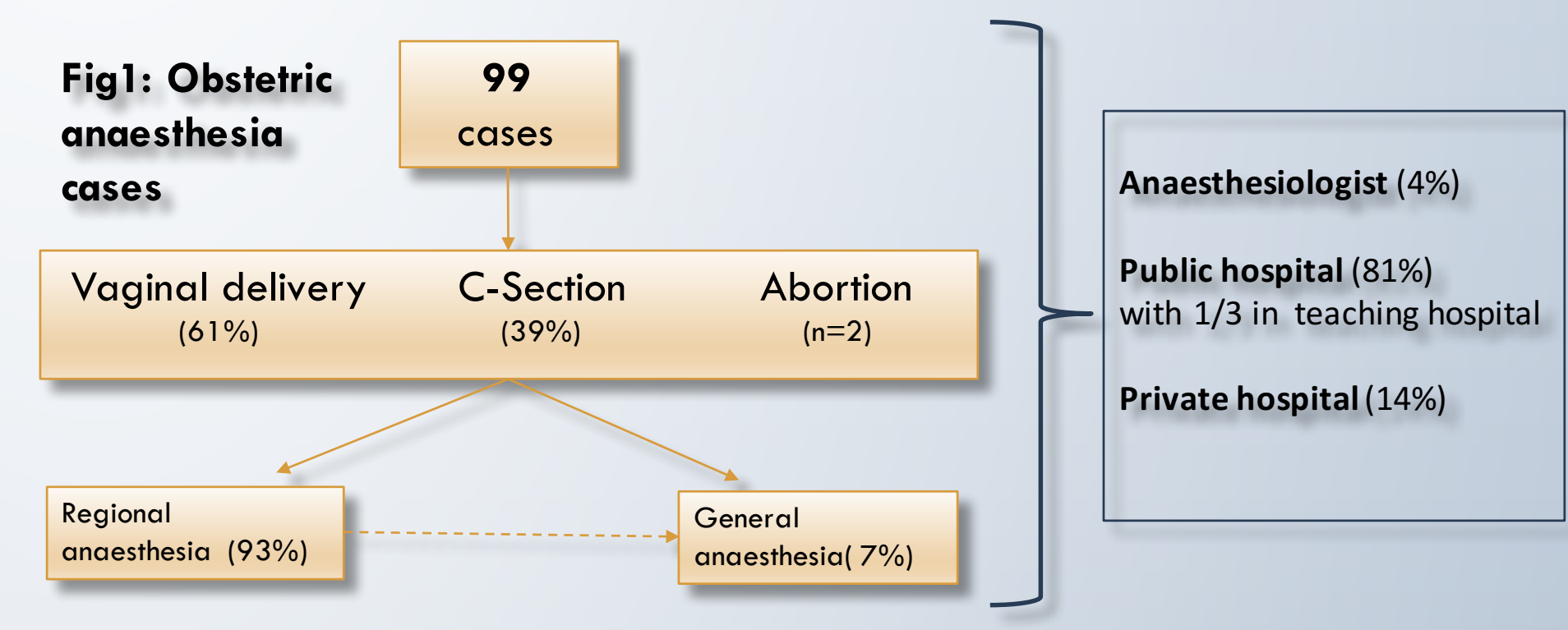

Fig 2: Rate of complications due to regional anaesthesia

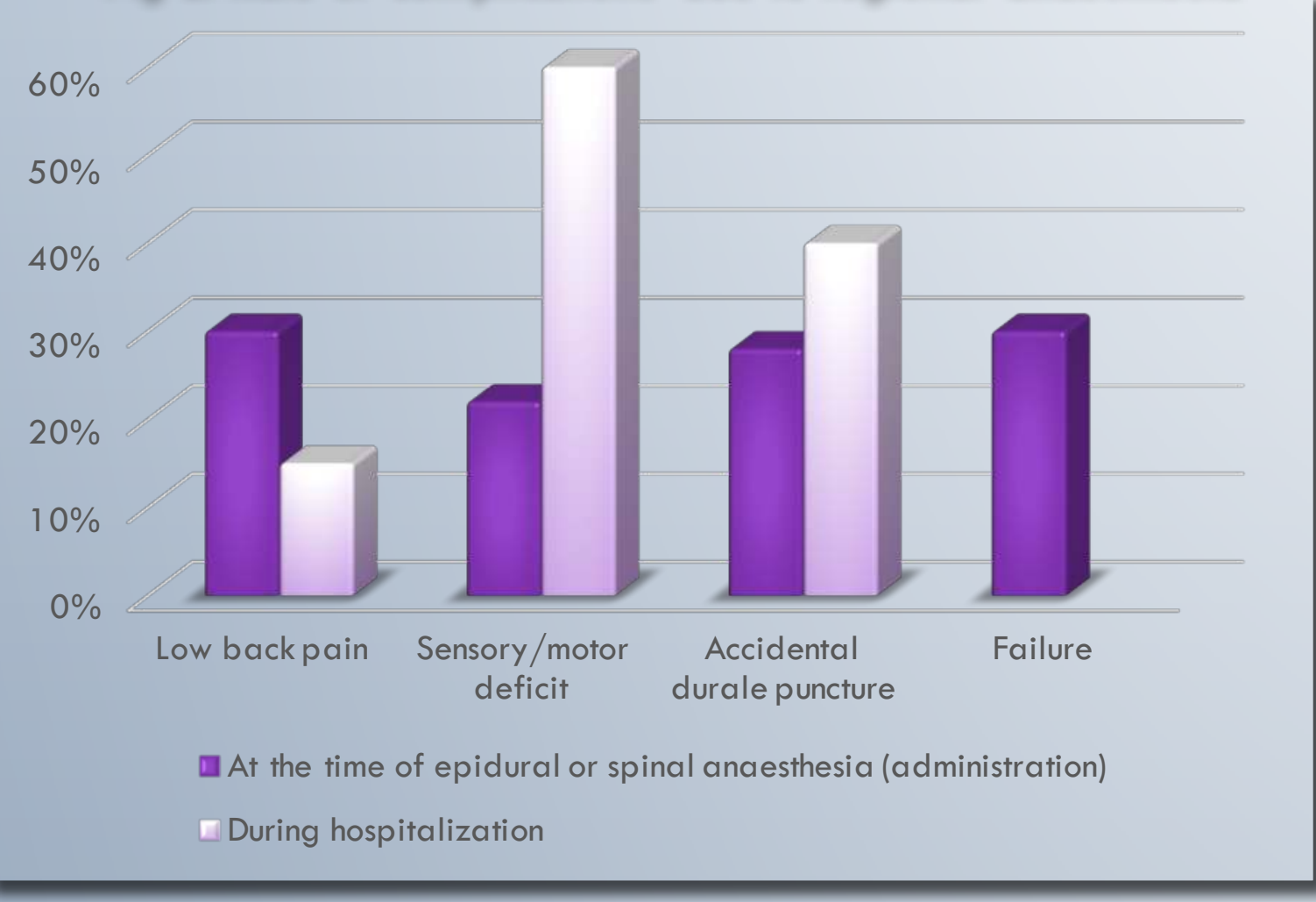

\section{Discussion:}

Claim in Obstetrics, related to anaesthesiaassociated complications, is rare. When they occur, regional anaesthesia is the main involved procedure.

To note, general anaesthesia has a ratio complications over frequency of utilization, higher than regional anaesthesia.

Medical malpractice is finally rarely established: this could be explained by the quality of information provided to patients and the good traceability of anaesthesia care in medical records.
The claims for regional anaesthesia (Fig 2) occurred during its administration (42\%) or after during hospitalization $(81 \%) \quad(>100 \%$ because of combined reports)

12 complications during regional anaesthesia (accidental dural puncture (ADP) or failure) required general anaesthesia (involving 1 respiratory arrest after ADP and 1 acute subdural hematoma on day 2). In addition one general anaesthesia caused complications with anaphylactic shock (succinylcholine) and inhalation after difficult intubation leading to brain damage.

The claims filed because of general anaesthesia were linked to two anaphylactic shocks (death after abortion and brain damage after Csection) and pelvic pain after abortion.

Finally there have been 54 brain damage (from monoparesis to vegetative coma), 2 deaths, 6 moral damages and 37 other causes.

Only 2 cases were settled by a civil court, the others amicably

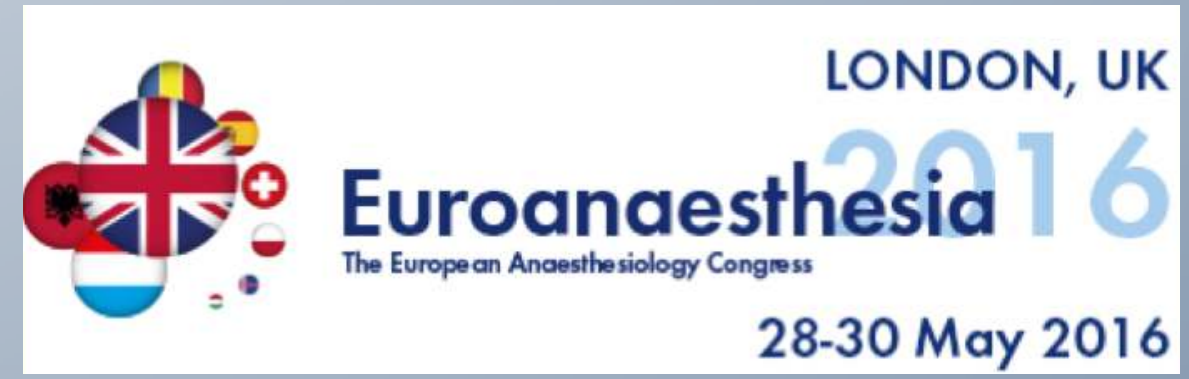

